\title{
Quantifying the effect of heat stress on daily milk yield and monitoring dynamic changes using an adaptive dynamic model
}

\author{
G. André, ${ }^{\star 1}$ B. Engel,† P. B. M. Berentsen,‡ Th. V. Vellinga, ${ }^{\star}$ and A. G. J. M. Oude Lansink‡ \\ *Livestock Research, Wageningen University and Research Centre, PO Box 65, 8200 AB Lelystad, the Netherlands \\ †Biometris, Wageningen University and Research Centre, PO Box 100, 6700 AC Wageningen, the Netherlands \\ łBusiness Economics Group, Wageningen University and Research Centre, PO Box 8130, 6700 EW Wageningen, the Netherlands
}

\begin{abstract}
Automation and use of robots are increasingly being used within dairy farming and result in large amounts of real time data. This information provides a base for the new management concept of precision livestock farming. From 2003 to 2006, time series of herd mean daily milk yield were collected on 6 experimental research farms in the Netherlands. These time series were analyzed with an adaptive dynamic model following a Bayesian method to quantify the effect of heat stress. The effect of heat stress was quantified in terms of critical temperature above which heat stress occurred, duration of heat stress periods, and resulting loss in milk yield. In addition, dynamic changes in level and trend were monitored, including the estimation of a weekly pattern. Monitoring comprised detection of potential outliers and other deteriorations. The adaptive dynamic model fitted the data well; the root mean squared error of the forecasts ranged from 0.55 to 0.99 $\mathrm{kg}$ of milk/d. The percentages of potential outliers and signals for deteriorations ranged from 5.5 to $9.7 \%$. The Bayesian procedure for time series analysis and monitoring provided a useful tool for process control. Online estimates (based on past and present only) and retrospective estimates (determined afterward from all data) of level and trend in daily milk yield showed an almost yearly cycle that was in agreement with the calving pattern: most cows calved in winter and early spring versus summer and autumn. Estimated weekly patterns in terms of weekday effects could be related to specific management actions, such as change of pasture during grazing. For the effect of heat stress, the mean estimated critical temperature above which heat stress was expected was $17.8 \pm 0.56^{\circ} \mathrm{C}$. The estimated duration of the heat stress periods was $5.5 \pm 1.03 \mathrm{~d}$, and the estimated loss was $31.4 \pm 12.2 \mathrm{~kg}$ of milk/cow
\end{abstract}

Received December 30, 2010.

Accepted May 30, 2011.

${ }^{1}$ Corresponding author: Geert.Andre@wur.nl per year. Farm-specific estimates are helpful to identify management factors like grazing, housing and feeding, that affect the impact of heat stress. The effect of heat stress can be decreased by modifying these factors.

Key words: dairy farming, heat stress, process control, precision livestock farming

\section{INTRODUCTION}

Heat stress occurs when dairy cows suffer from hyperthermia when they fail to maintain thermoneutrality with increasing ambient temperature and humidity. Higher-producing cows are more at risk than lowerproducing cows (Bianca, 1965), because high DMI results in increased metabolic heat increment. Heat stress leads to decreased milk production and changes in milk composition (Schneider et al., 1988; Abdel-Bary et al., 1992 ) as fat and protein content decrease (Bandaranayaka and Holmes, 1976; McDowell et al., 1976). Besides temperature, wind speed and humidity play a role, and McDowell et al. (1976) included humidity in their index for heat stress. Apart from climatological factors, the effect of heat stress depends on housing conditions and management (e.g., whether cows remain indoors or not; Bohmanova et al., 2007). Accurate measurement of the entry stage of heat stress is complicated (Kadzere et al., 2002). Berman et al. (1985) found an upper control temperature of 25 to $26^{\circ} \mathrm{C}$ for the thermoneutral zone in cows. In the aforementioned studies, heat stress is related to ambient temperature, registered near the cows. In practice, the ambient temperature is not ordinarily recorded on farms. Therefore, for operational on-farm use it is expedient to relate heat stress to daily temperature as recorded on meteorological stations in the region in which the farm is situated. This could help in timely signaling of the risk of heat stress and decreasing its negative effects.

The effect of heat stress depends on the specific farm situation. Hence, it is recommended to quantify the effect of heat stress using milk production data, collected in the farm-specific situation. Milk production data are 
available from management information systems that are increasingly used within dairy farms. Management information systems provide the basis for precision livestock farming, which is believed to contribute to more sustainable dairy production, both in ecological and economic terms (Banhazi and Black, 2009; Wathes, 2009). Wathes et al. (2005) concluded that precision livestock farming is an "embryonic technology" with great promise, but one that requires considerable research and development of models of the key biological and physical processes, with meaningful measures to control and monitor the production process (Frost et al., 1997).

Quantitative methods, developed and implemented for quality control of industrial processes (Montgomery, 2005), were proposed for animal production processes (Reneau and Lukas, 2006). Industrial processes usually can be fully controlled. Biological processes are inherently variable through dynamic changes due to age, reproduction, and interactions with the environment. Dynamic changes in level, trend, and cyclical patterns from serial processed data can be estimated by time series analysis (Pankratz, 1991). Deluyker et al. (1990) used time series analysis for modeling daily milk yield of individual cows, but focused only on level and trend. André et al. (2011) used a dynamic model to describe the effects of concentrate intake and milking interval length on individual daily milk production. This dynamic model was fitted following a Bayesian procedure for time series analysis (West and Harrison, 1997). This Bayesian procedure comprises a procedure for process monitoring and control and can be applied to herd mean milk production data.

The objective was to develop a dynamic adaptive model that provides an integrated method for (1) estimation of the effect of heat stress on milk production in the actual on-farm situation and (2) monitoring of level, trend, and weekly pattern of milk production. The approach allows for the detection of unexpected changes in daily milk production due to unanticipated events like illness.

\section{MATERIALS AND METHODS}

\section{Data from Experimental Farms}

The data set consisted of time series of observations of herd mean daily milk production from 6 experimental dairy farms during the period from January 1, 2003 to December 31, 2006. Milk yield per milking per cow was recorded electronically on each farm. The milk meters were checked at least once yearly and calibrated by the suppliers of the milking equipment. Table 1 provides several farm characteristics such as the feeding strategy, grazing during the summer, and roughage mixture of the silage during the winter. The roughage mixture was fed in summer when the cows were not grazing during the night or day. Aver Heino (AH) is an organic farm with Red Holstein cows. The other farms, Bosma Zathe (BZ), Cranendonck (CD), Hoorn (HO), Hightech (HT), and Zegveld (ZV) were conventional farms with Holstein-Friesian cows. At CD and ZV the cows were kept in 1 group and milked twice daily in a milking parlor. At HT the cows were kept in 1 group, but milked with an automatic milking system (AMS). At BZ, the cows were kept in 3 separate groups; 2 groups were milked in an AMS, and 1 group was milked twice daily in a milking parlor. At $\mathrm{HO}$, there were 5 groups, 4 milked in an AMS and 1 group milked twice daily in a milking parlor. The groups within a farm were pooled to calculate the herd mean daily milk production. At all farms, cows were in freestalls. The barns at HT and HO were ventilated barns with open side walls and, during warm days, mechanical ventilators were used to stimulate air circulation. The barns at AH, BZ, CD, and ZV were naturally ventilated by openings in the top of the sidewalls without using mechanical ventilation.

Table 1. Dairy farm characteristics in the Netherlands during the period from 2003 to 2006

\begin{tabular}{|c|c|c|c|c|c|c|}
\hline $\operatorname{Farm}^{1}$ & $\begin{array}{l}\text { Region in the } \\
\text { Netherlands }\end{array}$ & $\begin{array}{l}\text { Soil } \\
\text { type }\end{array}$ & $\begin{array}{l}\text { Summer } \\
\text { grazing }\end{array}$ & $\begin{array}{l}\text { Roughage } \\
\text { mixture } \\
\text { (proportion } \\
\text { grass:corn) }\end{array}$ & $\begin{array}{l}\text { Herd size } \\
\text { (no.) }\end{array}$ & $\begin{array}{l}\text { Milk yield } \\
(\mathrm{kg} / \mathrm{d})\end{array}$ \\
\hline $\mathrm{BZ}$ & North & Clay & Limited during the day & 0.70:0.30 & 125.0 & 26.4 \\
\hline $\mathrm{CD}$ & South & Sand & Day & $0.55: 0.45$ & 84.3 & 26.2 \\
\hline $\mathrm{HO}$ & Middle & Clay & No & $0.55: 0.45$ & 344 & 29.4 \\
\hline
\end{tabular}

${ }^{1} \mathrm{AH}=$ Aver Heino; BZ = Bosma Zathe; $\mathrm{CD}=$ Cranendonck; HO = Hoorn; HT = Hightech; ZV = Zegveld.

${ }^{2}$ Silage was fed in the winter and in the summer when the cows were not grazing. 
The farms were located at different regions in the Netherlands, and average daily temperature was recorded at the meteorological stations nearest the farms. The distances between the farms and the meteorological stations range from $10 \mathrm{~km}$ (BZ) to $55 \mathrm{~km}$ (AH). Figure 1 shows the average daily temperature recorded from 2003 to 2006 on the meteorological stations in the different regions of the Netherlands.

\section{Dynamic Model}

Herd mean daily milk yield depends on several factors, like feeding, lactation stage, and mastitis outbreaks. Furthermore, the effect of high temperatures on herd mean daily milk yield interacts with other factors like humidity, solar radiation, and physiological state. These factors and interactions depend on the

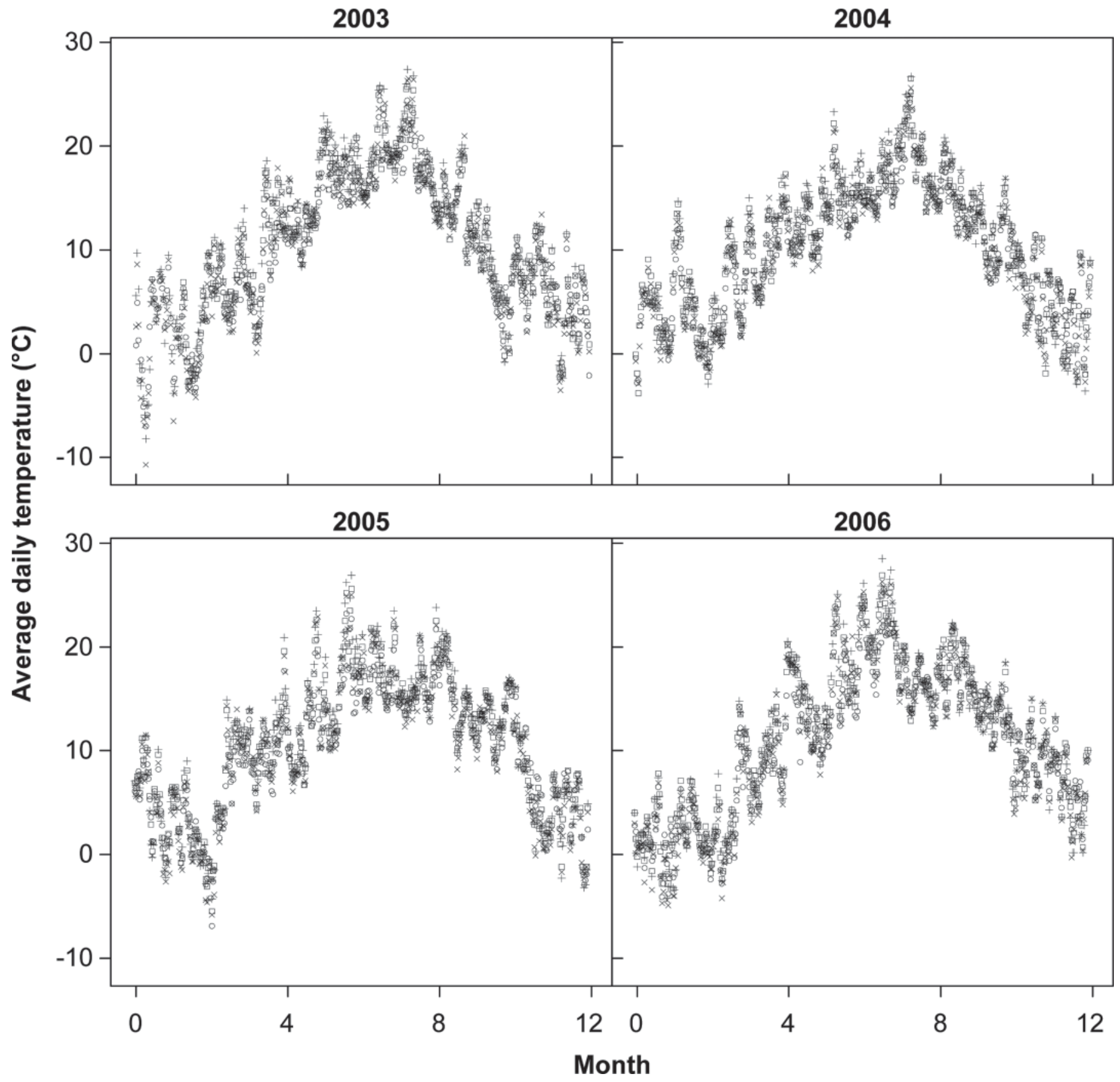

Figure 1. Average daily temperature from January 1, 2003 to December 31, 2006 at meteorological stations in different regions in the Netherlands: $\times$ middle-east, $\bigcirc$ north, + south, $\square$ middle. 
farm-specific situation and change over time. For that reason, a dynamic model was used, with time-dependent regression coefficients. Parameter estimates were updated daily to adapt to the actual on-farm situation. Hence, level and trend of herd mean daily milk adapted to changes in feeding, lactation stage, and mastitis outbreaks. The parameter for the effect of high temperatures was dynamic and adapted to the actual situation influenced by humidity and solar radiation.

A dynamic linear model consisted of an observation and a system equation. The observation equation 1 expressed herd mean daily milk yield $Y_{t}$ in terms of level $\mu_{t}$, weekday effect $\phi_{t, i}$, and heat stress effect $\gamma_{t}$ of a variable $X_{t}$, and a normally distributed observation error $v_{t} \sim N\left(0, V_{t}\right)$ with unknown variance $V_{t}$.

$$
Y_{t}=\mu_{t}+\phi_{t, i}+\gamma_{t} X_{t}+v_{t}
$$

The variable $X_{t}$ for heat stress, as derived by equation 2 , represented the accumulated temperature degrees above critical temperature $\tau$ during the past $\kappa$ days:

$$
X_{t}=\sum_{j=0 \ldots \kappa}\left(T_{t-j}-\tau\right) I_{T_{t-j}>\tau}
$$

where $T$ is the average daily temperature and indicator function $I$ is equal to 1 for $T>\tau$, and 0 otherwise. The system equation described the evolution of the parameters. The series level $\mu_{t}$ at time $t$ was modeled as a locally linear trend (see equation 3 ) with an incremental growth $\beta_{t-1}$ based on equidistant time points. The random errors $\omega_{t, 1}, \omega_{t, 2}$ represent random change in level and trend.

$$
\begin{gathered}
\mu_{t}=\mu_{t-1}+\beta_{t-1}+\omega_{t, 1} \\
\beta_{t}=\beta_{t-1}+\omega_{t, 2} .
\end{gathered}
$$

Some management actions, such as replacement of cows and change of pasture, were performed at specific days of the week, which might have affected milk yield on those days. Therefore, the model comprised an effect $\phi_{t, i}$ for each weekday $i$. These weekday effects $\phi_{t, i}$, as departures from the series level $\mu_{t}$, were assumed to sum to zero: $\sum_{i} \phi_{t, i}=0$. Moving from time $(t-1)$ to time $t$, moved from 1 weekday to another (cf. equation 4), where $\omega_{t, 3} \ldots \omega_{t, 9}$ represent random changes in the weekday effects.

$$
\begin{gathered}
\phi_{t, i}=\phi_{t-1, i+1}+\omega_{t, 3+i} \\
\phi_{t, 6}=\phi_{t-1,0}+\omega_{t, 9} .
\end{gathered}
$$

The effect of heat stress $\gamma_{t}$ was assumed locally constant (equation 5), involving random error $\omega_{t, 10}$.

$$
\gamma_{t}=\gamma_{t-1}+\omega_{t, 10}
$$

The system errors $\omega_{t, 1} \ldots \omega_{t, 10}$ were assumed normally distributed, with zero mean and variance matrix $W_{t}$. The system variance $W_{t}$ was estimated proportional to the covariance matrix of the model parameters. West and Harrison (1997) refer to this dynamic model as a second-order polynomial/form-free seasonal effects/ regression model.

\section{Parameter Estimation}

The dynamic model was fitted for each farm separately following a forward and backward procedure. In the forward procedure, only data of the series up to time $t$ were used to provide online parameter estimates by using updating recurrence relationships. So, the online parameter estimates were based on information from the past only. In the backward procedure, the retrospective parameter estimates were calculated using retrospective recurrence relationships, a form of backward filtering (smoothing). The retrospective parameter estimates were based on information from the whole series, resulting in a higher precision. For details about the calculation of the online and retrospective estimates see West and Harrison (1997).

The Bayesian method for parameter estimation allowed for decay of information from the past by using several discount factors, adjustable for different parts of the model. Values for discount factors were usual chosen between 0.8 and 1 , and the higher the factor, the smaller the decay. In this study, the discount factors were chosen according to the guidelines given by West and Harrison (1997): 0.9 for level and trend, 0.99 for effect of heat stress, and 0.975 for weekday effect. Level and trend were assumed more variable than the effects of heat stress and weekday, so for the latter, a higher discount factor was chosen. For heat stress, a relatively high discount factor was chosen because the effect could only be adequately estimated from data from a relatively long period that includes high temperatures. The unknown observation variance was estimated from the data using a discount factor of 0.95. After detection of potential outliers and other deteriorations (see Bayesian Monitoring below), discount factors were temporarily lowered to $0.85,0.975,0.95$, and 0.9 . This resulted in additional loss of information, to allow the system to readjust.

Duration $\kappa$ and critical temperature $\tau$ were nonlinear parameters and could not be simply estimated using the 
recurrence relationships. To estimate these parameters, an iterative procedure was followed by sequentially fitting models with fixed values for duration, increasing with steps of $1 \mathrm{~d}$, from 4 to $10 \mathrm{~d}$, and for critical temperature, increasing with steps of $0.5^{\circ} \mathrm{C}$, from 15.5 to $20^{\circ} \mathrm{C}$. The values that maximized the log-likelihood were retained as the maximum likelihood estimates for these nonlinear parameters and kept constant for the whole series. The total yearly loss in milk yield was obtained by accumulation of the daily effects of heat stress $\gamma_{t} X_{t}$ within years. The variance of the linear parameter $\gamma_{t}$ for the effect of heat stress was estimated and enabled the calculation of a $95 \%$ confidence interval for total yearly loss in milk yield. This interval was too narrow, because it did not reflect variability in the estimators for $\kappa$ and $\tau$, which was hard to assess.

\section{Bayesian Monitoring}

Detection of outliers and other deteriorations was based on calculation of the Bayes factor, the ratio of the likelihood that an observation fits well into the assumed (usual) model or into an alternative (outlier) model with a considerably inflated variance. Besides the Bayes factor, a cumulative Bayes factor and a run length were calculated, to detect whether the series of most recent observations showed evidence for slowly growing deterioration. When the Bayes factor was below the threshold 0.15, the observation was diagnosed as a potential outlier and discarded in the update of the parameters. When the cumulative Bayes factor was below the threshold 0.15 and (or) the run length was longer than 3, the last observation was not discarded, but an alert for slightly growing deterioration was given. In case of a potential outlier or an alert, the lower discount factors were used for updating parameter estimates. Consequently, the model parameters adapt faster to a possibly changed situation in the production process.

\section{Assessment of Model Adequacy}

Goodness of fit of the model was judged by graphical inspection of the forecast errors. The root mean squared error of the forecasts gave an indication of the variance of the errors in forecasts. The autocorrelation coefficient of successive forecast errors was calculated to evaluate the appropriateness of the choice of discount factors. For instance, a positive correlation would suggest that the discount factors were too high, and consequently, the model adapted too slowly. The retrospective parameter estimates provided an additional criterion for goodness of fit of the model in a comparison with the online parameter estimates.

\section{RESULTS}

Summarizing results are presented for all farms in the tables to show the farm-specific effect of heat stress. Daily results showing the development of the time series are shown in more detail for farm $\mathrm{HO}$ to clarify aspects of the analysis.

\section{Goodness of Fit, Forecasting, and Process Control}

In Table 2, the goodness-of-fit statistics are given per farm for the period from 2003 to 2006. The root mean squared error of the forecast errors ranged from 0.55 to $0.99 \mathrm{~kg}$ of milk/d, indicating that the variation coefficient was about $3 \%$ and a $90 \%$ probability interval for the forecasts ranged from 1 to $2 \mathrm{~kg}$ of milk/d. As expected, the root mean squared error of the forecast errors was lower for farms $\mathrm{BZ}$ and $\mathrm{HO}$, which had larger herds.

The autocorrelation between successive forecast errors ranged from 0.12 to 0.27 . The percentage of potential outliers and signals for deteriorations together ranged from 5.20 to $9.65 \%$.

Table 2. Goodness-of-fit statistics per farm, derived from the errors between forecasted and observed daily milk yield ${ }^{1}$

\begin{tabular}{llccc}
\hline Farm $^{2}$ & $\begin{array}{c}\mathrm{rMSE}^{3} \\
(\mathrm{~kg} / \mathrm{d})\end{array}$ & $\mathrm{Rho}^{4}$ & $\begin{array}{c}\text { Potential } \\
\text { outliers (\%) }\end{array}$ & $\begin{array}{c}\text { Deterioration } \\
\text { signals (\%) }\end{array}$ \\
\hline $\mathrm{AH}$ & 0.8496 & 0.1240 & 3.08 & 2.12 \\
$\mathrm{BZ}$ & 0.6645 & 0.2354 & 8.21 & 1.44 \\
$\mathrm{CD}$ & 0.8472 & 0.2201 & 5.31 & 3.29 \\
$\mathrm{HO}$ & 0.5456 & 0.1183 & 6.67 & 2.04 \\
$\mathrm{HT}$ & 0.9874 & 0.1274 & 4.31 & 2.46 \\
ZV & 0.8568 & 0.2749 & 6.02 & 2.19 \\
\hline
\end{tabular}

${ }^{1}$ The errors are classified as normal outlier, potential outlier, or signal for deterioration.

${ }^{2} \mathrm{AH}=$ Aver Heino; BZ = Bosma Zathe; CD = Cranendonck; HO = Hoorn; HT = Hightech; ZV = Zegveld.

${ }^{3}$ Root mean squared error.

${ }^{4}$ Autocorrelation coefficient between successive forecast errors. 


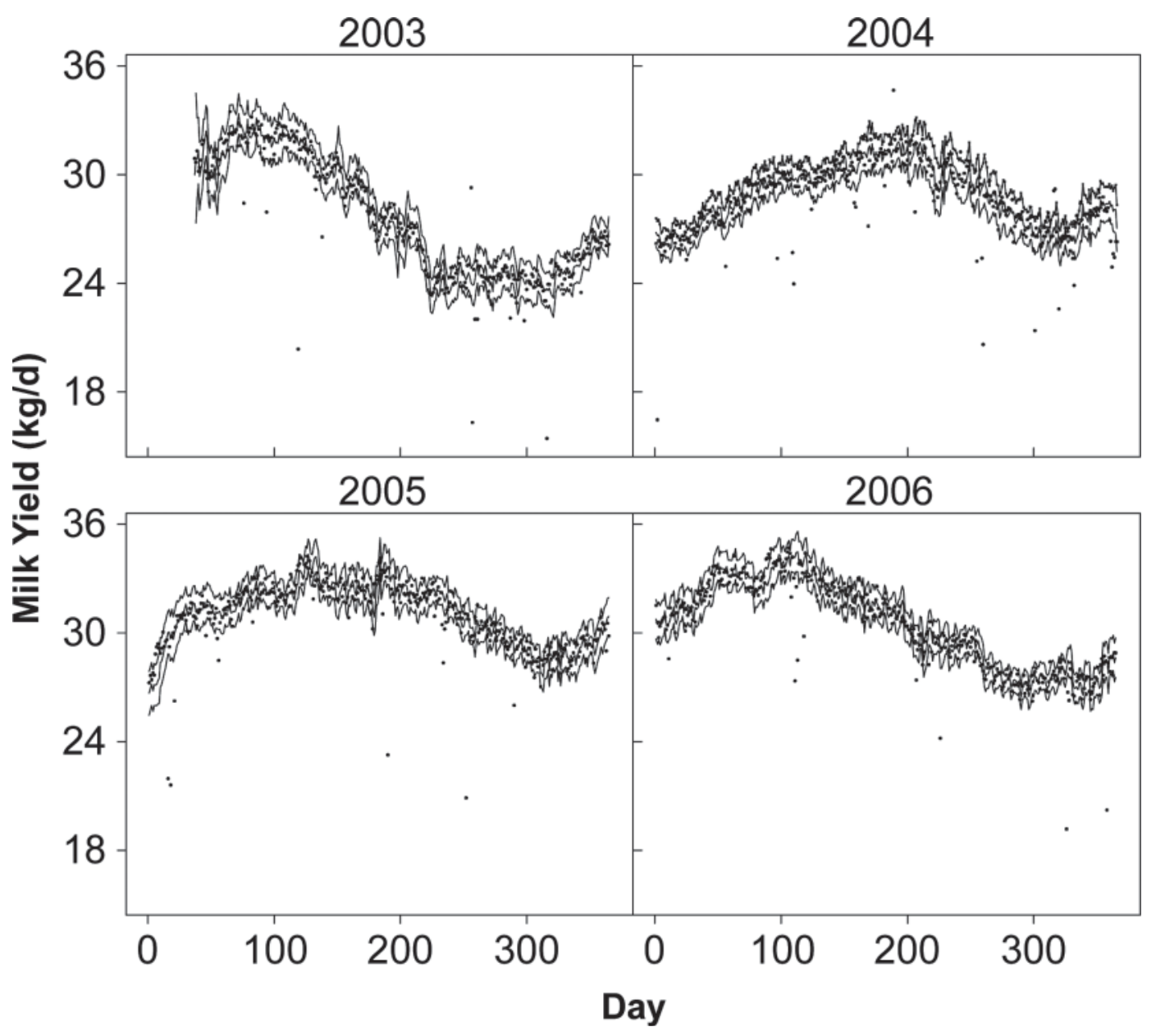

Figure 2. Observations (points) and forecasts (center line) with $90 \%$ probability interval (upper and lower line) for herd mean daily milk yield on farm Hoorn (HO) from January 1, 2003, to December 31, 2006.

In Figure 2, for farm HO, the observed milk yield per day is given together with the forecasts and the $90 \%$ probability interval over the whole period. The graphs show a yearly cyclical pattern with a maximum in spring and summer and a minimum in late autumn and winter. The weekday effects can be noticed in the short-term day-to-day variation of the forecasts. A decay in production during summer, caused by heat stress, can be seen, for instance around d 225 in 2004. Detailed results of these effects are presented next.

The observed milk yields per day were the raw data provided by the management systems on the farm. In Figure 2, it is seen that low values occurred and that a small number of positively deviating values existed that lie outside the forecast probability interval. In Figure 3 , the forecast errors are displayed and labeled to distinguish between normal forecast errors and potential outliers or other signals for deteriorations.

Large errors, deviating more than $2.5 \mathrm{~kg}$ of milk/d, were detected as potential outliers in most cases. These large errors were mainly due to technical failure of the equipment, resulting in recording errors in milk yield and number of cows. Also, small errors were detected as potential outliers and even small errors that lie within the forecast probability interval generated a signal for deterioration.

\section{Level and Trend}

The yearly cyclic pattern, already apparent in the forecasts (Figure 2), can be studied in more detail by decomposition of the development over time in level and trend. In Figure 4, the online and retrospective daily estimates for level and trend for farm $\mathrm{HO}$ are shown.

The increase in level (i.e., positive trend) during the winter and spring period were in agreement with the calving pattern. Besides this global development, shortterm fluctuations in level and trend are noticeable. It should be noted that effects of heat stress and weekday 


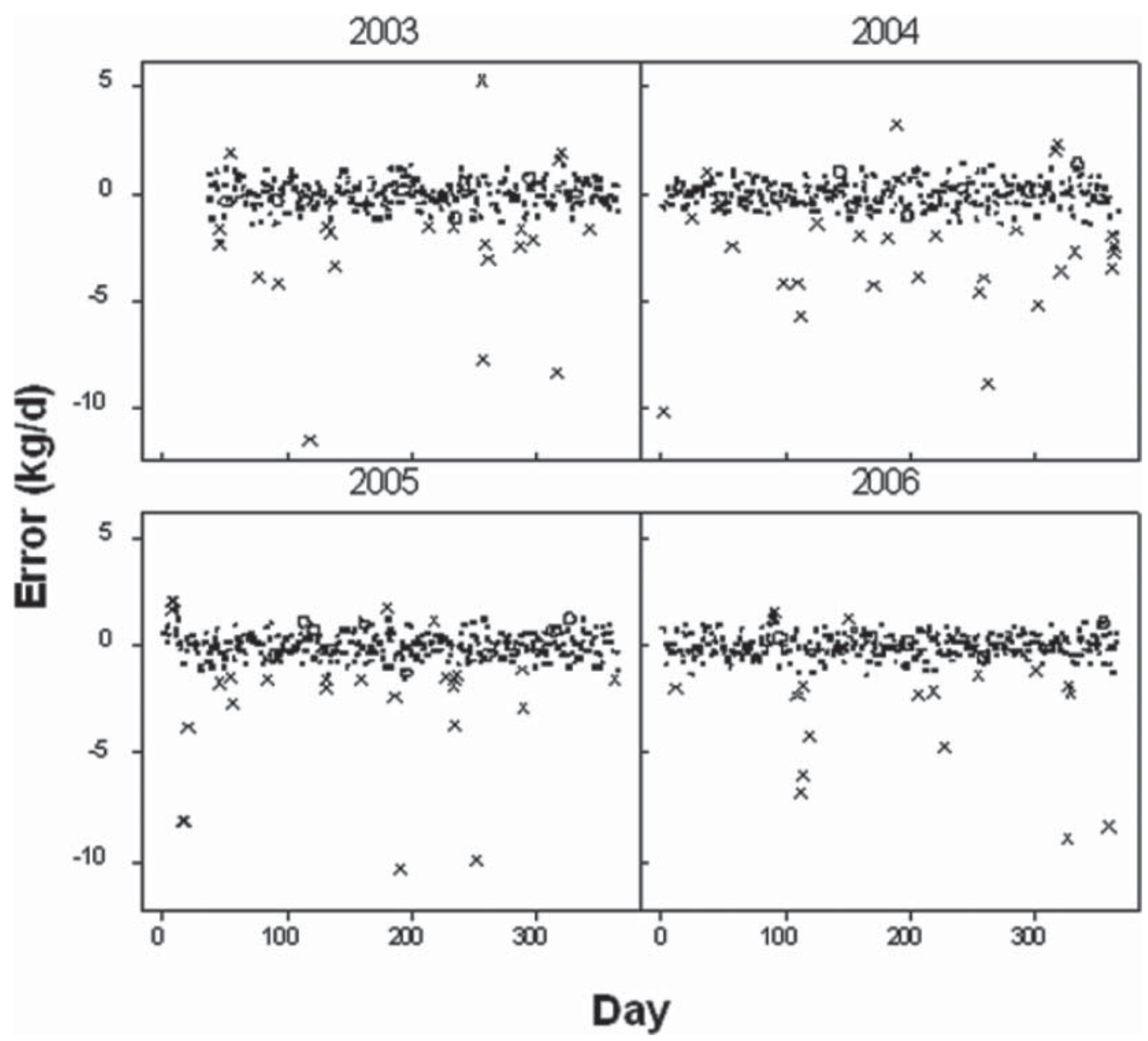

Figure 3. Development of error between forecasted and observed daily milk yield for farm Hoorn (HO) from January 1, 2003, to December 31,2006 . The errors are classified as normal outlier $(\cdot)$, potential outlier (x), or other signal for deterioration (o).

were not incorporated in the estimated level and trend. The $90 \%$ confidence interval for the retrospective estimates for level was considerably smaller than the $90 \%$ probability interval for the forecasts (Figure 2). The averaged standard error for the retrospectively estimated level was $0.19 \mathrm{~kg}$, which was lower than the average standard deviation of the forecasts of $0.55 \mathrm{~kg}$. So, retrospective estimates for level provide much more precise information about production level than observed and forecasted milk yield per day.

The averaged standard error for the retrospective estimated trend was $0.026 \mathrm{~kg}$, which means that, in general, an incremental change in level of about 0.05 $\mathrm{kg}$ of milk/d can be noticed as statistically significant. So, the retrospective estimated level and trend provide more precise information, which enables effective evaluation of herd mean daily milk yield, but afterward and not in real time.

\section{Weekly Pattern}

On all farms, a significant cyclic pattern of weekday effects was found during the period 2003 to 2006. In Figure 5, the retrospective estimated weekday effects on the farms ZV and HO are shown for May 2006 by way of an illustration. On farm ZV, a positive effect of $0.45 \mathrm{~kg} / \mathrm{d}$ occurred on Tuesdays, decreasing on the days thereafter to $-0.45 \mathrm{~kg} / \mathrm{d}$ on Fridays. From Saturday to Monday, almost no effect existed. This pattern can be explained by the pasture grazing strategy: the cows were rotated from a pasture after 3 to $4 \mathrm{~d}$, mostly on Tuesdays and Fridays. Similar patterns were found during the summer at the other farms that used grazing (AH, BZ, and CD).

An explanation for the weekday pattern at $\mathrm{HO}$, where grazing did not occur, is that each Monday a footbath with formaldehyde was placed in the entrance to the 

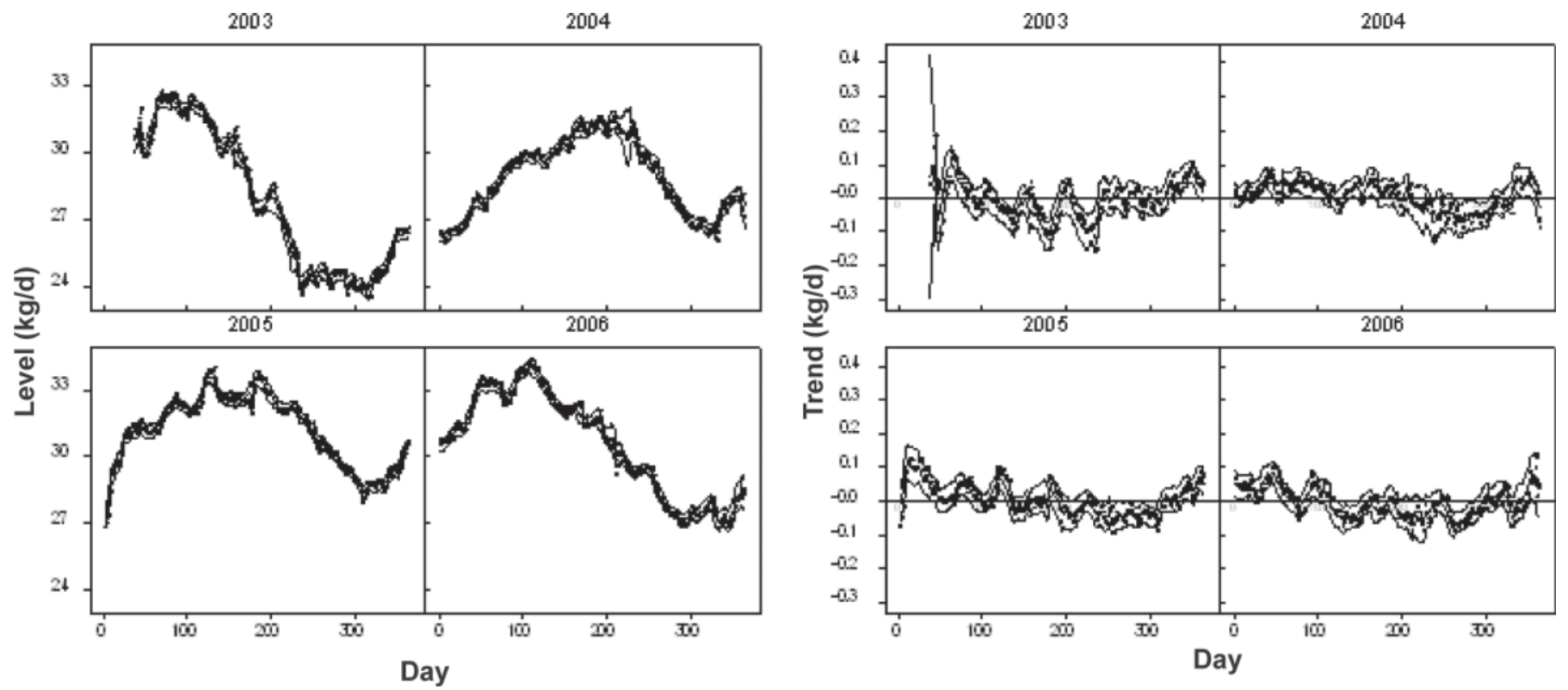

Figure 4. Estimated level (left) and trend (right) for herd mean daily milk yield on farm Hoorn (HO) from January 1, 2003, to December 31, 2006. Online estimates (points); retrospective estimates with $90 \%$ confidence interval (lines).

AMS, with a negative effect on the number of visits of the cows to the milking system, resulting in a lower milk yield per day. On farm HT, a foot bath was used in the same way and a negative effect on milk yield was found on Mondays. An alternative explanation might be that on Saturdays and Sundays, fewer management activities occurred in the barn, with a positive effect on average milk yield.

\section{Heat Stress}

The effect of heat stress is described in the model with the nonlinear parameters for critical temperature $\tau$ and duration $\kappa$ and the linear parameter $\gamma_{t}$ for loss in milk yield. The estimates for these parameters are in Table 3 . Variable $X_{t}$ counted the number of degrees above the critical temperature during the last $\kappa$ days. The daily loss in milk yield was calculated as the product of this variable with the linear parameter $\gamma_{t}$ for the effect of heat stress. In Figure 6, the daily loss in milk yield is given for farm $\mathrm{HO}$, based on the online and retrospective parameter estimates for heat stress, including the $90 \%$ confidence interval. The yearly accumulated daily loss is the area under the curve and gives the total loss in milk yield per cow per year as presented for all farms in Table 3.

In the Netherlands, loss in milk yield due to heat stress can occur during the summer from April (d 100)
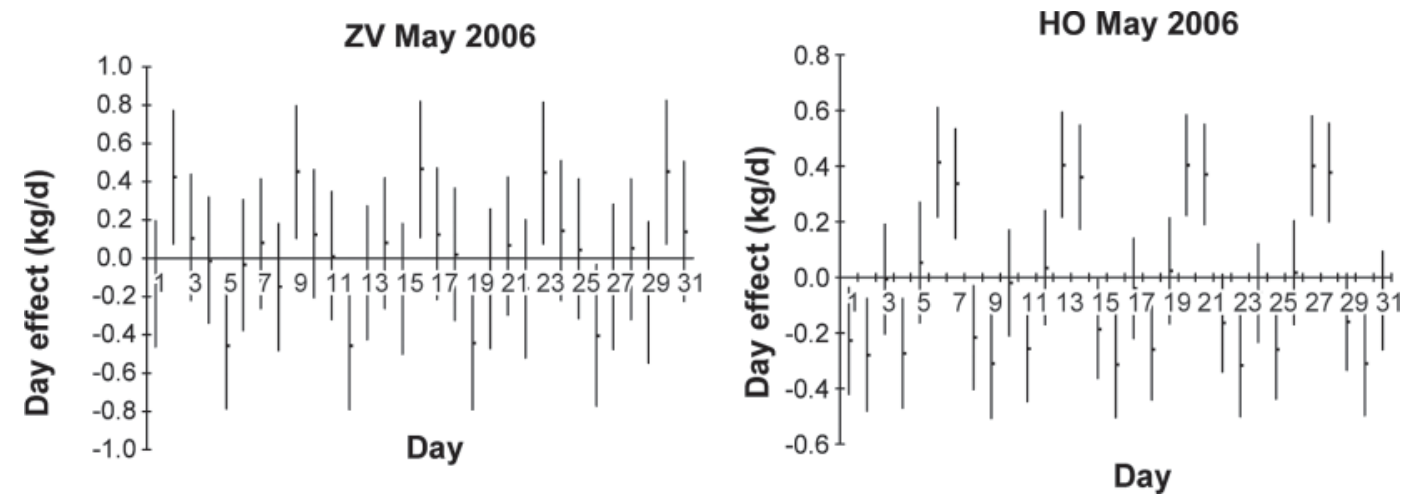

Figure 5. Retrospective estimates (points) with 90\% confidence interval (vertical bars) for weekday effects on farms Zegveld (ZV; left) and Hoorn (HO; right) during May 2006. May 1 is a Monday. 


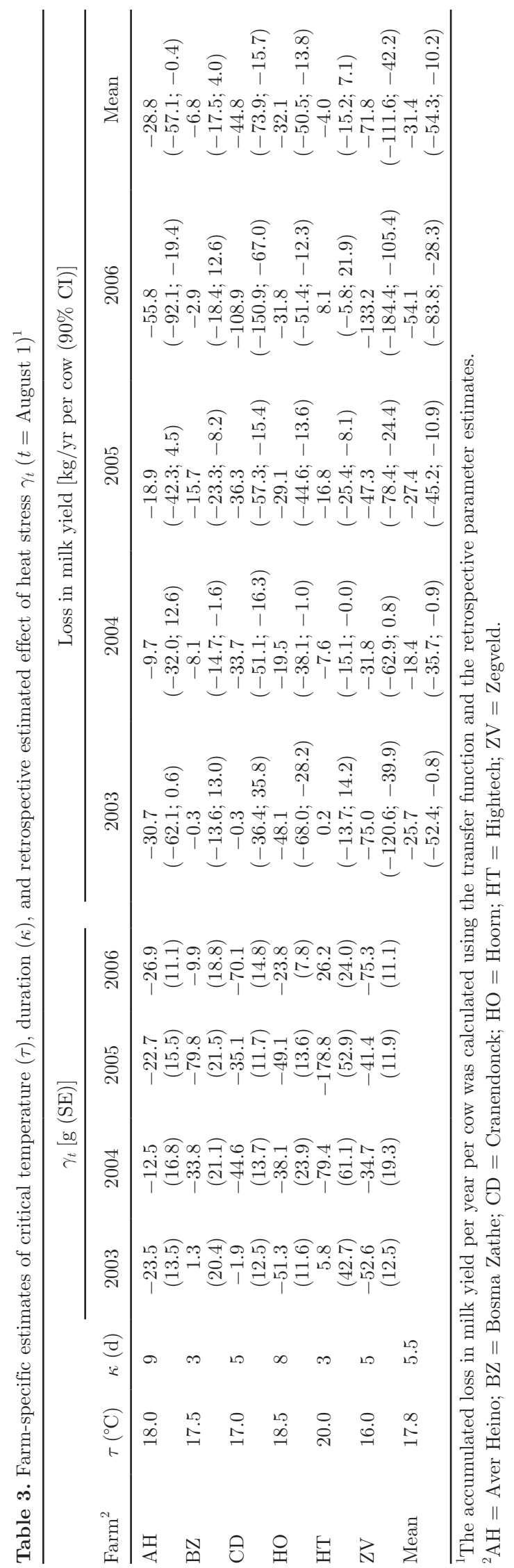

to October (d 300). From Figure 4, at HO, 3 to 7 periods with high temperature occurred and this had a negative effect on daily milk yield up to $2 \mathrm{~kg} / \mathrm{d}$ (summer 2003).

The total loss in milk yield due to heat stress per cow per year was $31.4 \mathrm{~kg}$, averaged over farms and years, but differed between years due to the variation in the weather conditions. The differences between farms were larger than the differences between years (Table 3) and can be explained by the specific situations and management strategies on the farms. The lowest losses were found at HT and BZ, mainly because on these farms, the estimated duration of the heat stress periods was low. At HT, the cows were kept indoors during summer in a modern open ventilated barn and during warm days, mechanical fans were used to stimulate air circulation. This explains the high critical temperature $\tau$ at HT. Moreover, at HT, the roughage mixture was enriched with more concentrates to ensure energy intake by the cows during warm periods. The lowest loss in milk yield at $\mathrm{BZ}$ can be related to the location near the coast in the north of the Netherlands where the temperature is lower and wind speed is higher compared with the regions in which the other farms were located.

Intermediate losses were found at $\mathrm{HO}$ and $\mathrm{AH}$. At $\mathrm{HO}$ and $\mathrm{AH}$, the duration of the heat-stress period was longer than at the other farms, indicating that cows recovered slower from heat stress. The housing at HO was similar to HT, but the barn and herd of HO were more than 4 times larger than HT, as a result of which ventilation might have been less effective. At CD and $\mathrm{ZV}$, the highest losses were found. The estimated critical temperature was lower than on the other farms, but the estimated duration was moderate. Both farms used grazing during summer, and, in combination with the losses found at $\mathrm{AH}$, it was concluded that grazing during warm days may have increased the negative effect of heat stress.

\section{DISCUSSION}

In our research, although attention was given to modeling and explanation of level, trend, and weekly cyclic pattern, the focus was on evaluation of the effect of heat stress on milk production at the herd level. The dynamic model can be applied at the individual level, comparable to the application in André et al. (2011), to estimate cow-specific effects of heat stress. However, because management actions to reduce the effect of heat stress are mostly applied at herd level, little need exists to gain insight into individual variation. Furthermore, estimation of individual effect requires long series of data and it might be difficult to estimate the effects of heat stress from individual daily milk yield data within lactation. Negative effects of heat stress on milk 


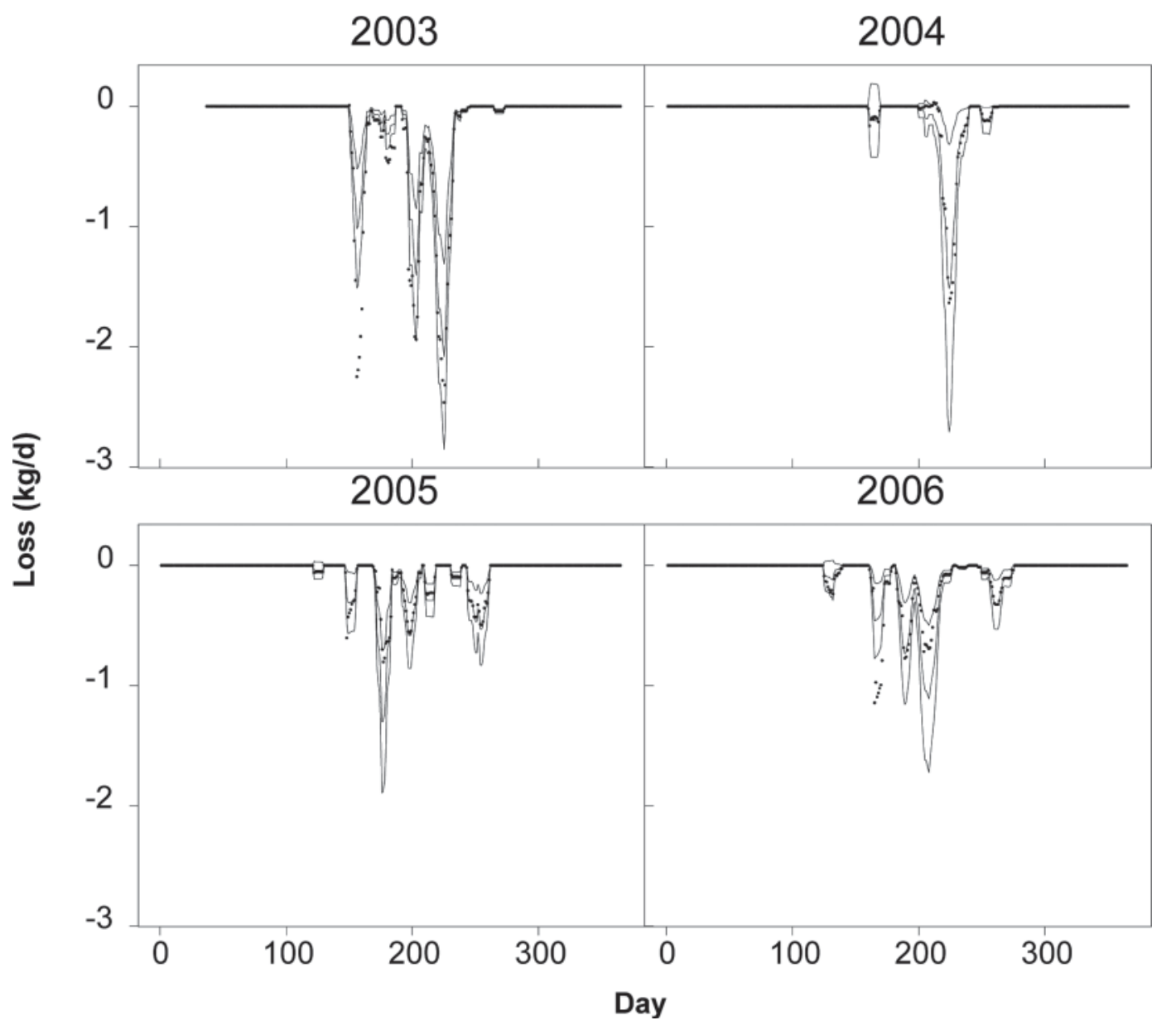

Figure 6. Online (points) and retrospective (lines, including upper and lower 90\% confidence limits) estimated daily loss in milk yield (kg/d) due to heat stress on farm Hoorn (HO) during the years 2003 to 2006.

production occurred when the average daily temperature was higher than the estimated critical temperature ranging from 16 to $20^{\circ} \mathrm{C}$. These values are lower than the upper critical temperature of 25 to $26^{\circ} \mathrm{C}$ for ambient temperature found for heat-adapted cows (Berman et al., 1985). The upper critical temperature varies with physiological state and other environmental conditions (Kadzere et al., 2002). Dairy cows in the Netherlands possibly are less heat adapted. Furthermore, when cows calve during winter and early spring, high temperatures in summer coincide with the peak of the lactation, when cows are more sensitive to heat stress (Kadzere et al., 2002). This might explain the relatively lower critical temperatures that were found. In many studies from the literature, ambient temperature was measured inside the barns near the dairy cows (Berman et al., 1985). The average daily temperature used in this study was derived from the outside temperature, which is often lower than the temperature inside naturally ventilated barns. Furthermore, it should be noted that the ambi- ent temperature ranges from a minimum at night to a maximum during the day. So, the ambient temperature of the cows might be above the upper control temperature during a considerable part of the day, even when the average daily outside temperature is between 16 to $20^{\circ} \mathrm{C}$. A low critical temperature indicated that the cows were at risk earlier in the day and for a longer period. The lowest values were found at the farms where the cows were grazing during summer. This indicated that the cows should be kept inside the barn during the hot periods of warm days, at least when the barn is cool and well ventilated. Environmental conditions that affect the critical temperature and the impact of heat stress are humidity, wind speed (outside), air change rate (inside), cloud cover, and solar radiation (Kadzere et al., 2002). These factors are interrelated and depend on the actual farm situation. With the dynamic modeling approach, as applied in this study, no need exists to model the effects and interactions of all of these factors explicitly, because critical temperature and duration 
are estimated per farm. Furthermore, the dynamic parameter for the effect of heat stress $\gamma_{t}$ adapts to changes in environmental conditions within farm.

In most studies the temperature-humidity index (THI) is used (St-Pierre et al., 2003; Bohmanova et al., 2007). In the Netherlands, within a site-specific onfarm location, humidity does not vary much during a hot period $(\mathrm{CV}=10.7 \%)$. Using only temperature has the advantage that temperature measurements of the meteorological stations can be replaced by on-farm measurements of temperature. Furthermore, temperature of the weather forecasts can be compared with the farmspecific estimated critical temperature to indicate the risk for heat stress in the near future and the expected loss in milk yield can be calculated using the parameter estimates for duration and effect of heat stress.

The estimated duration of the heat stress periods ranged from 3 to $9 \mathrm{~d}$. A long duration means that cows recover slowly from heat stress. An explanation might be that the reduced DMI caused residual effects. The delayed effects of heat stress supports West et al. (2003), who showed that mean air temperature and THI of $2 \mathrm{~d}$ earlier had the greatest effect on milk yield and DMI. Settivari et al. (2007) showed a negative effect on daily milk production up to $4 \mathrm{~d}$ after the end of an induced heat period. Linvill and Pardue (1992) used variables that counted the hours above a fixed threshold for THI up to the last $4 \mathrm{~d}$ to predict the effect of heat stress on milk production. The advantage of the model presented in this study is that the threshold and delay are both estimated from operational data, providing a farm-specific critical temperature and duration. Together with the linear parameter for heat stress, these parameters determine the total yearly loss in milk yield due to heat stress.

The loss in milk yield due to heat stress of $31.4 \mathrm{~kg} /$ cow per year is $0.32 \%$ in relation to the production of $9,855 \mathrm{~kg} /$ cow per year, averaged over farms. This loss is low in comparison to losses in the United States (St-Pierre et al., 2003), ranging from 68 (Wyoming) to 2,072 (Louisiana) $\mathrm{kg} / \mathrm{cow}$ per year. The dynamic model was fit following a Bayesian method for time series analysis, accompanied by a monitoring procedure for detection of outliers and other deteriorations. Not only were large errors detected, but small errors caused alerts. In case of alerts, it is up to the herdsman to diagnose the situation. Timely discovery and correcting causes for unexpected changes in daily milk production aid the farmer in improving the production process.

\section{CONCLUSIONS}

The adaptive dynamic model is appropriate for quantification of the effect of heat stress for each farm in its specific situation in terms of critical temperature, duration, and effect on milk production. The critical temperature can be used as an indicator for the risk on heat stress based on daily weather forecasts. The duration can be used to evaluate and improve management regarding grazing, feeding, and housing during warm periods. The adaptive dynamic model is appropriate for evaluation and monitoring level and trend of herd mean daily milk yield, including the estimation of weekday effects. The online estimates provide useful information to the farmer to evaluate the actual situation and the retrospective estimates provide a good insight afterward. The Bayesian procedure for time series analysis, accompanied with the monitoring procedure, followed by automatic intervention, is useful for process control. Detection of potential outliers and other deteriorations in the milk production process can be used as alerts to the farmer and might be helpful for improvement of dairy farm management.

\section{ACKNOWLEDGMENTS}

The authors are grateful to Edwin Bleumer (Livestock Research, Wageningen University and Research Centre, Wageningen, the Netherlands) for gathering the data. This project was funded by the Dutch Ministry of Agriculture, Nature and Food Quality (The Hague, the Netherlands).

\section{REFERENCES}

Abdel-Bary, H. T., M. M. Mohamed, H. I. Zaky, and A. A. Mohamed. 1992. Effects of season and month of calving on oestrous performance, services per conception and milk yield of Friesian cows in Egypt. Egypt. J. Anim. Prod. 29:229-253.

André, G., B. Engel, P. B. M. Berentsen, G. van Duinkerken, and A. G. J. M. Oude Lansink. 2011. Adaptive models for online estimation of individual milk yield response to concentrate intake and milking interval length of dairy cows. J. Agric. Sci. doi:10.1017/ S0021859611000311.

Bandaranayaka, D. D., and C. W. Holmes. 1976. Changes in the composition of milk and rumen contents in cows exposed to a high ambient temperature with controlled feeding. Trop. Anim. Health Prod. 8:38-46.

Banhazi, T. M., and J. L. Black. 2009. Precision livestock farming: A suite of electronic systems to ensure the application of best practice management on livestock farms. Austral. J. Multi-disciplinary Eng. 7:1-14.

Berman, A., Y. Folman, M. Kaim, M. Mamen, Z. Herz, D. Wolfenson, A. Arieli, and Y. Graber. 1985. Upper critical temperatures and forced ventilation effects for high-yielding dairy cows in a subtropical climate. J. Dairy Sci. 68:1488-1495.

Bianca, W. 1965. Reviews of the progress of dairy science. Section A. Physiology. Cattle in a hot environment. J. Dairy Res. 32:291345 .

Bohmanova, J., I. Misztal, and J. B. Cole. 2007. Temperature-humidity indices as indicators of milk production losses due to heat stress. J. Dairy Sci. 90:1947-1956.

Deluyker, H. A., R. H. Shumway, W. E. Wecker, A. S. Azari, and L. D. Weaver. 1990. Modeling daily milk yield in Holstein cows using time series analysis. J. Dairy Sci. 73:539-548. 
Frost, A. R., C. P. Schofield, S. A. Beaulah, T. T. Mottram, J. A. Lines, and C. M. Wathes. 1997. A review of livestock monitoring and the need for integrated systems. Comput. Electronics Agric. 17:139-159.

Kadzere, C. T., M. R. Murphy, N. Silanikove, and E. Maltz. 2002. Heat stress in lactating dairy cows: A review. Livest. Prod. Sci. 77:59-91.

Linvill, D. E., and F. E. Pardue. 1992. Heat stress and milk production in the South Carolina coastal plains. J. Dairy Sci. 75:2598-2604.

McDowell, R. E., N. W. Hooven, and J. K. Camoens. 1976. Effect of climate on performance of Holsteins in first lactation. J. Dairy Sci. 59:965-971.

Montgomery, D. C. 2005. Introduction to Statistical Process Control. 3rd ed. John Wiley \& Sons, New York, NY.

Pankratz, A. 1991. Forecasting with Dynamic Regression Models. John Wiley \& Sons, New York, NY.

Reneau, J. K., and J. Lukas. 2006. Using statistical process control methods to improve herd performance. Vet. Clin. North Am. Food Anim. Pract. 22:171-193.

Schneider, P. L., D. K. Beede, and C. J. Wilcox. 1988. Nycterohemeral patterns of acid-base status, mineral concentrations and digestive function of lactating cows in natural or chamber heat stress environments. J. Anim. Sci. 66:112-125.
Settivari, R. S., J. N. Spain, M. R. Ellersieck, J. C. Byatt, R. J. Collier, and D. E. Spiers. 2007. Relationship of thermal status to productivity in heat stressed dairy cows given recombinant bovine somatotropin. J. Dairy Sci. 90:1265-1280.

St-Pierre, N. R., B. Cobanov, and G. Schnitkey. 2003. Economic losses from heat stress by US livestock industries. J. Dairy Sci. 86(Suppl.):E52-E77.

Wathes, C. M. 2009. Precision livestock farming for animal health, welfare and production. Pages 411-419 in Sustainable Animal Production: The Challenges and Potential Developments for Professional Farming. A. Aland and F. Madec, ed. Wageningen Academic Publishers, Wageningen, the Netherlands.

Wathes, C. M., H. H. Kristensen, J.-M. Aerts, and D. Berckmans, 2005. Is precision livestock farming an engineer's daydream or nightmare, an animal's friend or foe, and a farmer's panacea or pitfall? Pages 33-47 in: Precision Livestock Farming '05. S. Cox, ed. Wageningen Academic Publishers, Wageningen, the Netherlands.

West, J. W., B. G. Mullinix, and J. K. Bernard. 2003. Effects of hot, humid weather on milk temperature, dry matter intake, and milk yield of lactating dairy cows. J. Dairy Sci. 86:232-242.

West, M., and J. Harrison. 1997. Bayesian Forecasting and Dynamic Models. 2nd ed. Springer-Verlag New York Inc., New York, NY. 